\title{
Of PES and other animals
}

\author{
SVEN WUNDER
}

Payments for environmental services (PES) are a direct conservation tool developed primarily by economists (e.g. Simpson \& Sedjo, 1996; Ferraro \& Kiss, 2002). An early review identified 287 operating or planned PES schemes (LandellMills \& Porras, 2002). Recently, PES trials have mushroomed and descriptions of them are now entering the peer-reviewed literature. Africa had lagged PES development elsewhere, with structural obstacles such as insecure land tenure and underdeveloped service-buyer institutions (Ferraro, 2009). This issue of Oryx remarkably holds three African PES experiences (Fisher, 2012; Gross-Camp et al., 2012; Lopa et al., 2012), exemplifying emerging interest in PES under African skies, along with one from Latin America (Goldman-Benner et al., 2012).

Lopa et al. (2012) describe a watershed scheme in Tanzania targeting upstream farmers in the Uluguru Mountains that deliver drinking water to Dar-es-Salaam. Current farming techniques result in nutrient mining and high soil erosion that have accelerated turbidity levels, raising water treatment costs for water companies and probably destabilizing seasonal flows. In response PES interventions have promoted terracing, agroforestry and other improved agricultural techniques. In 2010 village-level contracts delivered production inputs, technical assistance, and minor monetary rewards, proportional to changed practices, to 144 participant farmers.

What issues are interesting here? This PES programme closely resembles many in Latin America. A critical matter remains the mobilization of domestic funds. Implementers worked with the water companies over 6 years, establishing a viable business case before proceeding to local-level implementation. Although memoranda of understanding with upstream communities have been signed, apparently no continuously binding payment vehicle has yet been established. This is similar to the case of Los Negros, Bolivia (Asquith et al., 2008). What is holding service users back? Do they doubt the assumed hydrology linkages? Is it lack of faith in the providers and/or implementing intermediaries, and in PES institutional sustainability? Or do buyers rather trust they can free-ride on external funding, lacking a proper tradition and culture of payment? Often we need to better understand the motives and behaviour of service buyers before PES schemes can become workable.

Fisher (2012) describes a carbon forestry project in Uganda, focusing on how external PES incentives affect intrinsic environmental motivations. She finds multiple local (monetary

SVEN WUNDER Center for International Forestry Research (CIFOR), Rua do Russel, 450/601, CEP 22210-10, Rio de Janeiro, Brazil

E-mail s.wunder@cgiar.org and in-kind) benefits and costs associated with the PES-induced reforestation. PES thus become adoption subsidies, aimed at marginally tipping a complex balance in favour of environmentally friendly land uses. The results on motivation are mixed: some participants clearly react positively to short-term payments whereas for others longer-term intrinsic motivations dominate. Notwithstanding local environmental services from trees the main economic argument for reforestation is future timber revenues. Hence, assumed carbon 'permanence' beyond PES payment horizons becomes dubious: planted trees will become normal livelihood assets, which can de facto be liquidated according to household needs and opportunities. PES incentives should thus allegedly be better temporally aligned with service delivery.

We face here the classical temporal problem of reforestation projects: provision (especially labour) costs are frontloaded visa-vis backloaded service delivery from growing trees. Paying people proportionally to carbon sequestration would render reforestation economically inviable to most landholders. Fisher recommends more integrated project approaches. However, pure PES with more effective sanctions is another option. In Ecuador, for example, individual landowners delivered a lien on land or assets that was triggered upon non-compliance (Wunder \& Alban, 2008). When landowners are extremely asset-poor, other cross-conditionalities could still be applied. Tough conditional enforcement may be unpopular but is vital to commercial PES transactions as opposed to 'soft' agreements tending to encourage erratic compliance. Furthermore, just $1 \%$ of residents participated in the Ugandan programme and so the attitudes found may not easily be replicable to programmes with broader PES participation.

Gross-Camp et al. (2012) undertook a PES trial in Rwanda, remunerating local communities over 2 years for improved compliance with the forest-resource use restrictions of the preexisting but contested nearby Nyungwe National Park. Payments are made after monitored compliance, differentiated according to rates of infractions encountered in forest walks. However, payments were generally lower than the opportunity costs of abstaining from forest use. Control sites (controlimpact) and baselines (before-after) were used to isolate PES effects. After PES treatment there were lower, but not significant, infraction levels than in the baseline but impacts on control groups were similar. Livelihoods were reportedly improved and payment modes were locally perceived as fair.

Why would people participate in a scheme that delivers dramatically fewer benefits than costs? Gross-Camp et al. suggest recipients treasured some non-monetary PES benefits and also kept illegality of their use in mind. There may also be another interpretation: that many people simply didn't comply, which could explain why infractions did not fall significantly. 
Why should they comply with a scheme that undercompensates their opportunity costs, and that will end in just 2 years? Under this design, non-compliance is the only way they could yield net livelihood benefits. Getting the incentives right is always vital to PES. Nevertheless, this study provides an interesting case study of how a PES 'carrot' may or may not work on top of a preexisting but dysfunctional legal 'stick' (park enforcement).

Goldman-Benner et al. (2012) describe the efforts to create seven water funds that help preserve both hydrological and biodiversity-based ecosystem services in the Andes. Typically water users pay into trust funds, together with other sources (e.g. public entities, conservation organizations). Resources can then be used as counterpart for donor projects, or even reach a size where conservation can be financed from interest payments alone, allegedly making conservation financially self-sustainable. The authors argue the advantages of trust funds, which they consider PES, although many de facto compromise on conditionality and additionality. PES theory should thus learn from successfully applied conservation practice, and broadly recognizing water funds as PES would ease donor-funding mobilization.

Doubtlessly water funds have benefitted conservation in the Andes. They also feature ecosystem-based financing, which in many PES schemes has been an Achilles heel. But charging for service uses alone does not make them PES. The authors analytically seem to confuse the conservation finance ('user pays') and incentive ('provider receives') sides of PES. Obviously, service users pay into water funds, which may help consolidate conservation finance. It may also have drawbacks, such as when trust-fund participants internally disagree over spending priorities, or when increasingly centralistic governments start threatening the independence of funds. More importantly, funds may come to struggle for capital preservation in the high-default, low-interest financial environment of today. The conservation finance verdict on trust funds thus still seems to be out.

Yet, the arguably decisive PES criterion is whether providers receive conditional payments. Two of the trust-fund partners mentioned (CEDERENA in Ecuador, Fundacion Natura in Bolivia) actually use conditional landowner payments in their PES implementation. However, to my knowledge all of the seven main trust funds described have so far refrained from paying people conditionally for changed land-use practices: 'nobody receives'! Instead, financed activities focus on the generic family of integrated conservation and development projects (ICDPs), sometimes complemented by improved law enforcement. Whether money is accumulated in funds or paid out directly has nothing to do with these spending decisions. There may be good reasons for not paying people conditionally (e.g. unclear land tenure, illegal uses), and less good ones (innate ideological resistance), but invariably they take us outside the PES realm.

These four contributions will enrich the debate about PES and other more or less related animals. I would like to stress two overarching issues.

Firstly, definitions and concepts matter. We should not let funding fashions tempt us into squeezing all good things under a single attractive PES umbrella (Goldman-Benner et al.) and along the way lose the notion of what it is all about. As is recognized in the other three articles, doing ICDPs is not PES-the latter were actually born as a direct alternative to the former (Ferraro \& Kiss, 2002). Getting the taxonomy of policy instruments right is just as important as distinguishing different animal specimens.

Secondly, economics is at the heart of PES but does not always receive adequate attention in design of PES schemes. If payments offered fall short of providers' conservation opportunity costs by up to an order of magnitude (Gross-Camp et al.), or remain around just USD 10 per household per year (Lopa et al.), how could we possibly expect them to become fair, livelihoodsimproving and environmentally efficient? The complexity of contextual drivers must always be appreciated. But if PES are chosen as an instrument the underlying assumption must be that economic incentives can make a key difference. Hence, basic ex ante economic diagnostics are required to understand what payment modes and sizes are needed to achieve that difference. The recently broadened PES debate towards fairness, poverty and intrinsic conservation attitudes is important but if that comes at the cost of not getting the basic economics right, then PES schemes are bound to fail.

\section{References}

Asquith, N., Vargas, M.T. \& Wunder, S. (2008) Selling two environmental services: in-kind payments for bird habitat and watershed protection in Los Negros, Bolivia. Ecological Economics, $65,675-684$.

Ferraro, P. (2009) Regional review of payments for watershed services: sub-Saharan Africa. Jounal of Sustainable Forestry, 3-4, 525-50.

Ferraro, P. \& Kiss, A. (2002) Direct payments to conserve biodiversity. Science, 298, 1718-1719.

Fisher, J. (2012) No pay, no care? A case study exploring motivations for participation in payments for ecosystem services in Uganda. Oryx, 46, 45-54.

Goldman-Benner, R.L., Benitez, S., Boucher, T., Calvache, A., Daily, G., Kareiva, P. et al. (2012) Water funds and payments for ecosystem services: practice learns from theory and theory can learn from practice. Oryx, 46, 55-63.

Gross-Camp, N., Martin, A., Mcguire, S., Kebede, B. \& Munyarukaza, J. (2012) Payments for ecosystem services in an African protected area: exploring issues of legitimacy, fairness, equity and effectiveness. Oryx, 46, 24-33.

Landell-Mills, N. \& Porras, I.T. (2002) Silver Bullet or Fool's Gold? A Global Review of Markets for Forest Environmental Services and Their Impact on the Poor. International Institute for Environment and Development, London, UK.

Lopa, D., Mwanyoka, I., Jambiya, G., Massoud, T., Harrison, P., Ellis-Jones, M. et al. (2012) Towards operational payments for water ecosystem services in Tanzania: a case study from the Uluguru Mountains. Oryx, 46, 34-44.

Simpson, R. \& SEDJO, R.A. (1996) Paying for the conservation of endangered ecosystems: a comparison of direct and indirect approaches. Environment and Development Economics, 1, 241-257.

Wunder, S. \& Albán, M. (2008) Decentralized payments for environmental services: the cases of Pimampiro and PROFAFOR in Ecuad. Ecological Economics, 65, 685-98. 